\title{
CCE 92-05 Intercomparison of AC-DC Voltage Transfer Standards at High Frequencies (1-50 MHz)
}

\author{
Cees J. van Mullem
}

\begin{abstract}
From August 1995 to May 1998, the CCE 92-05 intercomparison of ac-dc voltage transfer standards at high frequencies was carried out. Two travel standards were measured by 15 national standards institutes. The results in the frequency range from 1 to $50 \mathrm{MHz}$ show a good agreement between the majority of participants. The span of the majority of the reported ac-dc differences at $50 \mathrm{MHz}$ is less than $1000 \mu \mathrm{V} / \mathrm{V}$, which is similar to a previous intercomparison but with a greater number of participants.
\end{abstract}

Index Terms - AC-DC transfer, intercomparison, measurement standards, thermal converters.

\section{INTRODUCTION}

$\mathbf{T}$ HE PRIMARY LF ac-dc transfer standards (up to $1 \mathrm{MHz}$ ) are realized by using single or multijunction thermal converters (SJTC or MJTC) [1]. The ac-dc voltage transfer difference and the corresponding uncertainty have reached the level of several tenths of $\mu \mathrm{V} / \mathrm{V}$ in the audio frequency range [2]. In the high-frequency range, coaxial thermal converters (UHF-type) or calorimetric systems are commonly used as primary voltage standards [3]-[8]. Furthermore, the transfer difference and uncertainty strongly increase with frequency in this range.

In instrumentation, significant progress has been made to ac calibration and measurement equipment. An added option is the so-called wideband option, which generates or measures ac voltage in the megahertz range with relatively high accuracy.

To be able to establish a worldwide traceability for ac-dc transfer at high frequencies, the Comité Consultatif d'Electricité (CCE) decided to organize an international comparison. There had never been an extensive CCE intercomparison, only an (informal) intercomparison between six laboratories has been carried out [9]. In the meantime, the CCE has pointed out this type of intercomparison as one of the key comparisons.

\section{SCOPE OF THE INTERCOMPARISON}

During the last decades, several ac-dc transfer intercomparisons have been carried out concerning the low-frequency range (up to $1 \mathrm{MHz}$ ) [2]. The scope of the presented comparison is to extend the frequency range up to $50 \mathrm{MHz}$ with a relatively small uncertainty of the ac-dc transfer difference (see Table I).

Manuscript received July 2, 1998.

The author is with NMi Van Swinden Laboratorium (VSL), 2600 AR Delft, The Netherlands.

Publisher Item Identifier S 0018-9456(99)02870-3.
TABLE I

Measurement Parameters for the Two Traveling Standards

\begin{tabular}{l|c|c|c}
\hline Standard & Input & Required frequencies & Optional frequencies \\
\hline TS-HF & $4 \mathrm{~V}$ & $1,10,30$ and $50 \mathrm{MHz}$ & $0,5,70$ and $100 \mathrm{MHz}$ \\
\hline TS-A55 & $3 \mathrm{~V}$ & $1,10,30$ and $50 \mathrm{MHz}$ & $0,5,70$ and $100 \mathrm{MHz}$ \\
\hline
\end{tabular}

To cover the transition from the $\mathrm{LF}$ ac-dc voltage transfer to the RF voltage in $50 \Omega$ systems, the frequency range extends over $0.5 \mathrm{MHz}$ to $100 \mathrm{MHz}$.

\section{TRAVELING STANDARDS}

Two traveling standards are used in the intercomparison.

- VSL Calculable HF AC-DC Transfer Standard (TS-HF) [3], [4]: This ac-de standard consists of a 5-mA thermoelement in series with an (in-house) range resistor. This combination has a nominal input voltage of $4 \mathrm{~V}$ and a corresponding output voltage of $7 \mathrm{mV}$. The standard is equipped with a type- $\mathrm{N}$ male input connector.

- Fluke A55 Thermal Converter (TS-A55): A commercial Fluke A55-3 V thermal converter is used as the second traveling standard, which is equipped with a GR-874 input connector. It has a nominal input voltage of $3 \mathrm{~V}$ and also a 7-mV output voltage.

\section{A. AC-DC Transfer Difference}

The ac-dc transfer difference $\delta$ of the traveling standards is defined as

$$
\delta \equiv\left(V_{\mathrm{ac}}-V_{\mathrm{dc}}\right) / V_{\mathrm{dc}}
$$

where $V_{\mathrm{ac}}$ is the rms value of the applied ac voltage, and $V_{\mathrm{dc}}$ is the mean value of the direct and reversed dc voltages, which produces the same output voltage of the standard as $V_{\mathrm{ac}}$.

\section{B. Connectors}

The middle of a Tee-connector is used as the reference plane for the ac-dc transfer measurements. Due to the fact that the input connectors are different, problems can arise due to compatibility of the connectors. Therefore, a special Tee has been provided, which has at the input a type- $\mathrm{N}$ female connector and at the output on one side a type- $\mathrm{N}$ female and on the other side a GR-874 connector. 


\section{Measurement Setup}

To characterize the measurement setup used for systematic errors and to be independent of the reference standards, the participants are asked to measure the two traveling standards against each other by using the supplied Tee connector. The result of this measurement can be used by the participant to have a consistency check of their measurement setup. On the other hand, these errors can be detected by the pilot laboratory when the reported ac-dc transfer differences are analyzed.

\section{PARTICIPATING LABORATORIES}

The NMi Van Swinden Laboratorium is the pilot laboratory for this intercomparison. The long-term stability of the traveling standards due to transportation was not characterized before. Therefore, the pilot laboratory has scheduled three check measurements during the intercomparison. Due to serious transportation problems, it finally ends up with five check measurements.

The participants are given in the chronological order in which they have participated.

\section{A. Participants}

1) NMi Van Swinden Laboratorium (VSL), The Netherlands, C. J. van Mullem.

2) Physikalisch-Technische Bundesanstalt (PTB), Germany, D. Janik.

3) D. I. Mendeleyev Institute for Metrology (VNIIM), Russia, V. S. Alexandrov.

4) National Office of Measures (OMH), Hungary, A. Jakab.

5) Slovenian Institute of Quality and Metrology (SIQ), Slovenia, Z. Svetik and A. Razpotnik.

6) National Physics Laboratory (NPL), U.K., G. Jones (up to $1 \mathrm{MHz}$ ).

7) Laboratoire Central des Industries Électriques (LCIE), France, M. Valon and L. Erard.

8) AREPA Test \& Kalibrering A/S, Denmark, T. Lippert.

9) Office Fédéral de Métrologie (OFMET), Switzerland, M. Flüeli.

10) Sverige Provnings-och Forkskningsinstitut (SP), Sweden, K.-E. Rydler (up to $30 \mathrm{MHz}$ ).

11) Centro Español de Metrologia (CEM), Spain, J. M. Balmisa, M. Neira, S. Ramiro, and M. Martínez.

12) National Institute of Standards and Technology (NIST), USA, J. Kinard and G. Free.

13) National Measurement Laboratory (NML), Australia, I. F. Budovsky and J. Petranovic.

14) National Physical Laboratory (NPLI), India, V. K. Rustagi and A. K. Govil.

15) Korean Research Institute of Standards and Science (KRISS), South Korea, J. H. Kim and S. W. Kwon.

\section{LABORATORY PROCEDURES AND STANDARDS}

The laboratory procedures and reference standards used by the participants have been described in more or less detail in the reports. In cases when the report contains a minimum of
TABLE II

Reference STANDARDS AND MEasurement Procedure Used by the Institutes

\begin{tabular}{|c|c|c|c|}
\hline Institute & $\begin{array}{c}\text { Primary standard } \\
\quad<=1 \mathrm{MHz}\end{array}$ & $\begin{array}{c}\text { Primary standard } \\
>1 \mathrm{MHz}\end{array}$ & Measurement system \\
\hline VSL & $\begin{array}{l}\text { VSL HF SJTC } \\
(S J C+700 \Omega)\end{array}$ & $\begin{array}{l}\text { VSL HF SJTC } \\
(\mathrm{SJTC}+700 \Omega)\end{array}$ & $\begin{array}{l}\text { ac-dc transfer system } \\
\text { (automatic) }\end{array}$ \\
\hline РТВ & PTB MITC & $\begin{array}{l}\text { Coaxial calorimeter } \\
\text { (dual load type) }\end{array}$ & $\begin{array}{l}\text { ac substitution system } \\
\text { (automatic) }\end{array}$ \\
\hline VNIIM & $\begin{array}{l}\text { VNIM converter } \\
(\mathrm{SJTC}+1 \mathrm{k} \Omega)\end{array}$ & $\begin{array}{l}\text { VNIIM converter } \\
(\mathrm{SITC}+1 \mathrm{k} \Omega)\end{array}$ & No information \\
\hline OMH & OMH MTTC & $\begin{array}{l}\text { Calorimetric voltage } \\
\text { standard }\end{array}$ & $\begin{array}{l}\text { ac-dc transfer system } \\
\text { (automatic) }\end{array}$ \\
\hline SIQ & EUR HF SJTC & EUR HF SJTC & RF-de manual system \\
\hline NPL & SJTC $+900 \Omega$ & not participating & ac-dc transfer system \\
\hline LCIE & Holt 20 converter & Holt 20 converter & RF-dc manual system \\
\hline AREPA & EUR HF SJTC & EUR HF SJTC & ac-dc transfer system (aul) \\
\hline OFMET & EUR HF SJTC & EUR HF SJTC & ac-dc transfer system (aut.) \\
\hline SP & EUR HF SJTC & EUR HF SJTC & ac-dc transfer system (aurt.) \\
\hline CEM & $\begin{array}{l}\text { MJTC (PTB-cal.) } \\
\text { EUR HF SJTC } \\
\end{array}$ & EUR HF SJTC & ac-dc transfer system (aut.) \\
\hline NIST & NIST S TTC + $1 \mathrm{k} \Omega$ & NIST SJTC & ac-dc transfer system (aut) \\
\hline NML & NML TC & Twin line calorimeter & Aut. Comparison system \\
\hline NPLI & NPLI MUTC & $\begin{array}{l}\text { Calorimetric voltage } \\
\text { standard }\end{array}$ & $\begin{array}{l}\text { Serni-aut. Comparison } \\
\text { system }\end{array}$ \\
\hline KRISS & $\begin{array}{l}\text { KRISS MJTC } \\
\text { (PTB type +cal) }\end{array}$ & $\begin{array}{l}\text { RF power and } \\
\text { impedance standard }\end{array}$ & ac-dc transfer system (aut.) \\
\hline
\end{tabular}

information or large ac-dc deviations have been observed, the participant has been asked to give additional information.

In most cases, the reference standards for frequencies up to $1 \mathrm{MHz}$ and the higher frequencies are different. In Table II these reference standards for the two frequency ranges are given. Several European national institutes (such as OFMET, SP, CEM, SIQ, and AREPA) also use the VSL calculable HF ac-dc transfer standard (the EUR HF SJTC) as primary standard, the same type of instrument as the traveling standard TS-HF. These standards are calibrated by VSL. Other institutes use their own developed and characterized coaxial type of thermal converters or calorimetric systems as primary reference standards.

The measurement system for almost all institutes is a (semi-) automatic system to compare a traveling standard against their reference standard. In general, the ac-dc measurement consists of an input signal sequence dc+, ac, dc-, ac, dc + , etc. Some institutes use a two-step method to determine the ac-dc difference-first the ac-ac(ref) measurement and second the ac(ref)-dc measurement. The reference frequency is chosen between $1 \mathrm{kHz}$ and $100 \mathrm{kHz}$. The outputs of the standards are read simultaneously. Depending on the system, this is done directly by DVM's and/or the difference between the two standards to be compared is taken. The number of measurements differs from institute to institute. In general, 


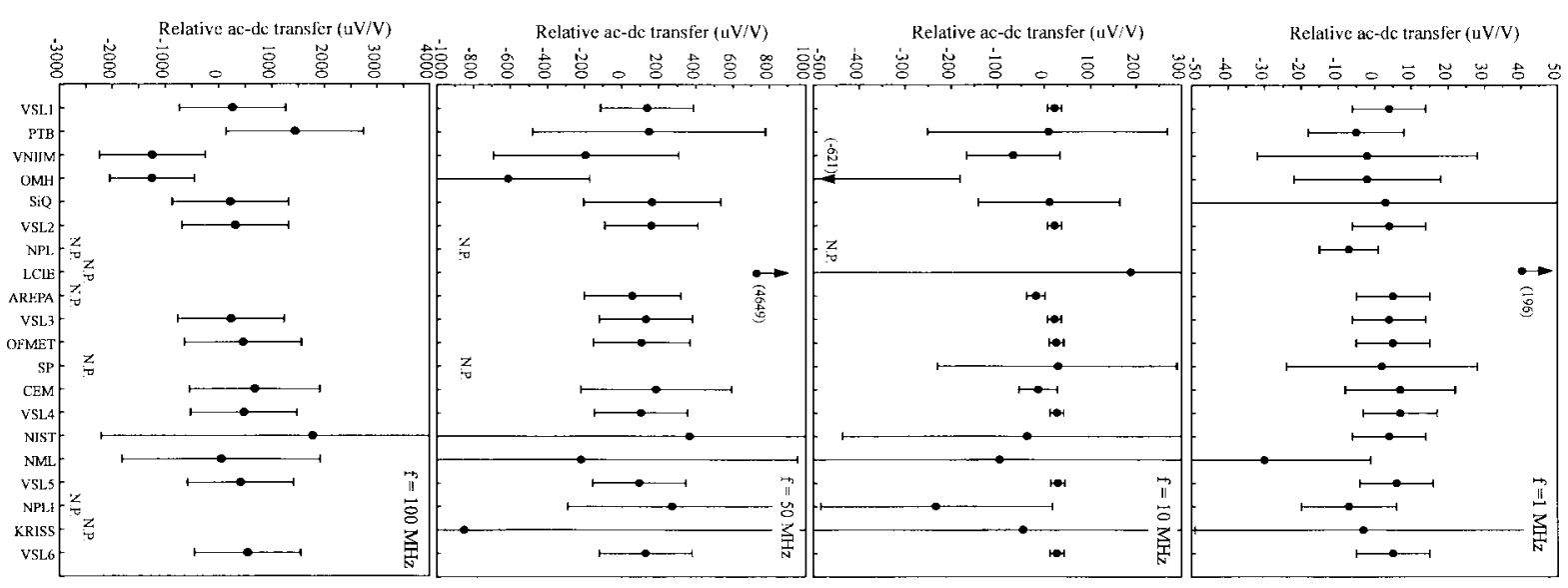

Fig. 1. Relative ac-dc transfer difference for the frequencies of $(1,10,50$, and 100) MHz for the TS-HF traveling standard (N.P.: not participating).

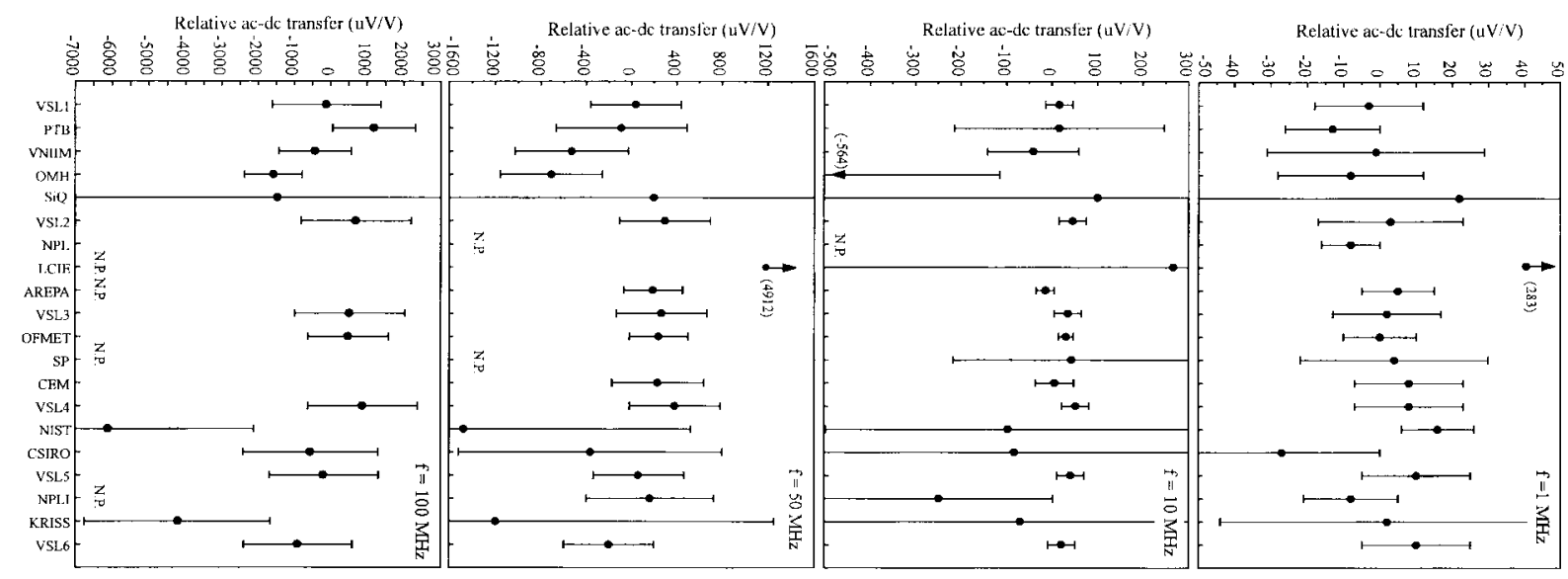

Fig. 2. Relative ac-dc transfer difference for the frequencies of $(1,10,50$, and 100) $\mathrm{MHz}$ for the TS-A55 traveling standard (N.P.: not participating).

measurements have been carried out in several days with 5-10 cycles per single measurement to obtain a mean value of the ac-dc transfer difference.

\section{UNCERTAINTY STATEMENTS}

The participants have been asked to report the uncertainty analysis in accordance with [10]. Most of them have provided a detailed uncertainty calculation in their report. However, some participants just reported the total uncertainty.

The type A evaluation is based on the number of measurements taken. The type B evaluation is divided into several independent contributions for which the pilot laboratory has proposed a minimum set. The main contribution is given by the reference standard used. For all institutes, this term is dominating the uncertainty calculation. Other reported uncertainty sources are the Tee connector, the measurement setup, and the reproducibility of the measurements.

From the reported uncertainty calculations, it is concluded that the determination of the uncertainty of the reference standard is essential. This part is not given in the reports but this is necessary to evaluate the uncertainties in detail to come to a worldwide agreement in the scope of a key comparison.

\section{RESULTS OF THE INTERCOMPARISON}

Figs. 1 and 2 present the results for the two traveling standards for the frequencies $(1,10,50$, and 100) MHz. The given relative ac-dc transfer is the difference between the reported value and the calculated mean value which is the average of all reported $\delta$ 's with skipping extreme values. The uncertainty bars are the reported $k=1$ values.

The check measurements carried out by the pilot laboratory indicate that the TS-HF has a very stable behavior over time. However, the TS-A55 seems to be less stable but this can be caused by overloading during the intercomparison (reported at least once by a participant). Also, during a check measurement, the transfer differences of the TS-A55 showed instabilities, although they are small compared to the specified uncertainty.

The results at $1 \mathrm{MHz}$ are in close agreement with each other. However, one institute is completely out of the range and another is $30 \mu \mathrm{V} / \mathrm{V}$ away for the mean. The obtained results are similar to the published results for the last LF ac-dc intercomparison [2]. The scatter of the results increases with the frequency. But these deviations are mostly covered by the specified uncertainty. The overall agreement for the frequency range from $10 \mathrm{MHz}$ to $50 \mathrm{MHz}$ is good. In addition, for most 
institutes the uncertainties are strongly increasing at $10 \mathrm{MHz}$ due to the transition from LF to HF ac-dc reference standards.

Even at $100 \mathrm{MHz}$, the results show a quite good agreement. However, half of the eight presented results are obtained by using a reference standard that is based on the VSL calculable HF ac-dc standard [3], [4]. In combination with the results obtained for the other frequencies, it is concluded that there is a minimal influence of the measurement setup on the ac-dc transfer for this type of reference standard.

\section{CONCLUSIONS}

In May 1998, the intercomparison of ac-dc voltage transfer standards at high frequencies was completed. The final results in the frequency range from $1 \mathrm{MHz}$ to $50 \mathrm{MHz}$ show a good agreement between the majority of participants. The calculated deviations from the mean value are covered by the specified uncertainty. The present intercomparison clearly indicates that a detailed evaluation of the uncertainty of the reference standard is necessary to come to a worldwide agreement in this field of measurements.

\section{ACKNOWLEDGMENT}

All participants are gratefully thanked for their good cooperation during the running of the intercomparison and for respecting the time schedule as closely as possible.

\section{REFERENCES}

[1] M. Klonz, "Current developments in accurate ac-dc transfer measurements," IEEE Trans. Instrum. Meas., vol. 44, pp. 363-366, 1995.

[2] _ "CCE comparison of ac-dc voltage transfer standards at the lowest attainable level of uncertainty," IEEE Trans. Instrum. Meas., vol. 46, pp. 342-346, 1997.
[3] M. Nomair and C. J. Harmans, "High accuracy calculable ac-dc transfer standards for the LF-30 MHz frequency range," IEEE Trans. Instrum. Meas., vol. 38, pp. 342-345, 1989.

[4] C. J. van Mullem, W. J. G. D. Janssen, and J. P. M. de Vreede, "Evaluation of the calculable high frequency ac-dc standard," IEEE Trans. Instrum. Meas., vol. 46, pp. 361-364, 1997.

[5] J. R. Kinard and T. X. Cai, "Determination of ac-dc difference in the 0.1-100 MHz frequency range," IEEE Trans. Instrum. Meas., vol. 38, pp. 360-367, 1989.

[6] D. X. Huang, M. L. Chen, and S. Z. He, "RF-DC difference of coaxial thermal standards," IEEE Trans. Instrum. Meas., vol. 39, pp. 313-317, 1990.

[7] H. Gierke, L. Grno, D. Janik, and K. Münter, "Automatic RF voltage calibration with a primary voltage standard up to $1 \mathrm{GHz}$," IEEE Trans. Instrum. Meas., vol. 42, pp. 519-523, 1993.

[8] R. F. Clark, P. S. Filipski, and D. C. Paulusse, "Improvements in the NRC ac-dc transfer capabilities," IEEE Trans. Instrum. Meas., vol. 44, pp. 365-368, 1997.

[9] J. R. Kinard, Z. Zhen, D. X. Huang, G. Rebuldela, D. Janik, and J. de Vreede, "Intercomparison of thermal converters at NIM, NIST, PTB, SIRI and VSL from 10 to $100 \mathrm{MHz}$," IEEE Trans. Instrum. Meas., vol. 42, pp. 618-621, 1993.

[10] Guide to the Expression of Uncertainty in Measurement, 1st ed. BIPM/IEC/IFCC/ISO/IUPAP/OIML, 1993.

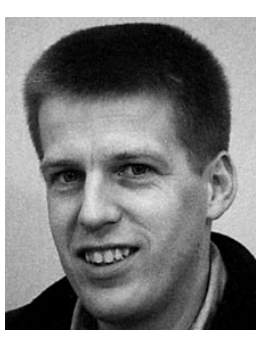

Cees J. van Mullem was born in Gouda, The Netherlands, in 1964. He received the M.Sc. and $\mathrm{Ph} . \mathrm{D}$. degrees in electrical engineering from the University of Twente, Enschede, The Netherlands, in 1989 and 1993, respectively.

In 1994, he joined the Department of Electricity and Magnetism, Nmi Van Swinden Laboratorium (the Dutch National Standards Laboratory), Delft, The Netherlands. His main interests are the development and maintenance of ac-dc transfer standards, especially in the frequency range from $100 \mathrm{kHz}$ to $100 \mathrm{MHz}$, DC-LF high precision measurement techniques, and RF power measurements. Hence he has been involved in several intercomparisons in the field of the ac-dc transfer. 